\title{
Pain Assessment in Impaired Cognition (PAIC): content validity of the Dutch version of a new and universal tool to measure pain in dementia
}

This article was published in the following Dove Press journal:

Clinical Interventions in Aging

\author{
Annelore $\mathrm{H}$ van Dalen-Kok' \\ Wilco P Achterberg' \\ Wieke E Rijkmans' \\ Sara A Tukker-van Vuuren' \\ Suzanne Delwel ${ }^{2,3}$ \\ Henrica CW de Vet ${ }^{4}$ \\ Frank Lobbezoo 2,5 \\ Margot WM de Waal' \\ 'Department of Public Health and \\ Primary Care, Leiden University \\ Medical Centre, Leiden, ${ }^{2}$ Department \\ of Oral Kinesiology, Academic Centre \\ for Dentistry Amsterdam (ACTA), \\ University of Amsterdam and VU \\ University Amsterdam, ${ }^{3}$ Department \\ of Clinical Neuropsychology, Faculty \\ of Behavioral and Movement Sciences, \\ VU University, ${ }^{4}$ Department of \\ Epidemiology and Biostatistics, \\ The EMGO Institute for Health \\ and Care Research, VU University \\ Medical Center, ${ }^{5}$ MOVE Research \\ Institute Amsterdam, VU University, \\ Amsterdam, the Netherlands
}

Objectives: Detection and measurement of pain in persons with dementia by using observational pain measurement tools is essential. However, the evidence for the psychometric properties of existing observational tools remains limited. Therefore, a new meta-tool has been developed: Pain Assessment in Impaired Cognition (PAIC), as a collaborative EU action. The aim is to describe the translation procedure and content validity of the Dutch version of the PAIC.

Methods: Translation of the PAIC into Dutch followed the forward-backward approach of the Guidelines for Establishing Cultural Equivalence of Instruments. A questionnaire survey was administered to clinical nursing home experts ( 20 physicians and 20 nurses) to determine whether the PAIC items are indicative of pain and whether items are specific for pain or for other disorders (anxiety disorder, delirium, dementia, or depression). To quantify content validity, mean scores per item were calculated.

Results: Eleven items were indicative of pain, for example, "frowning," "freezing," and "groaning." Fifteen items were considered to be pain-specific, for example, "frowning," "curling up," and "complaining." There were discrepancies between the notion of pain characteristics according to nurses and physicians, especially in the facial expressions domain.

Discussion: Within the body movement domain, PAIC items correspond well with the clinical experience of the physicians and nurses. However, items in the facial expressions and vocalizations domains need further study with respect to item reduction. Also, differences were revealed in the notion of pain characteristics between physicians and nurses, suggesting the need for more interdisciplinary education on pain in dementia.

Keywords: content validity, dementia, education, nursing home, observational pain measurement tool, pain

\section{Introduction}

Detection of pain in persons with dementia is challenging due to loss of ability to communicate and to the diverse presentation of pain. ${ }^{1}$ Therefore, in these individuals, observational pain measurement tools play an important role in the detection and measurement of pain. However, in clinical practice, it is often difficult to distinguish pain-related behavior from behavioral symptoms related to other disorders, such as anxiety disorder, delirium, and depression, or to dementia-related behaviors.

Over the years, many observational pain measurement tools have been developed, including PAINAD, ${ }^{2}$ PACSLAC,${ }^{3}$ and MOBID- $2 .{ }^{4}$ However, a systematic review of systematic reviews showed that there is limited evidence for the reliability, validity, feasibility, or clinical utility of these tools; the authors concluded that no specific available tool can be recommended for use in clinical practice. ${ }^{5}$ Moreover, nurses
Correspondence: Annelore $\mathrm{H}$ van Dalen-Kok

Department of Public Health and Primary Care, Leiden University Medical Centre, Hippocratespad 2I, Zone V0-P, PO Box 9600, 2300 RC Leiden, the Netherlands

Tel $+3 \mid$ 7| 5268438

Fax +3I 7| 5268259

Email a.h.van_dalen@lumc.nl
Clinical Interventions in Aging 2018:13 25-34

25

Dovepress in 0

http://dx.doi.org/| $0.2147 / C|A . S| 4465$ | (c) (7) 2018 van Dalen-Kok et al. This work is published and licensed by Dove Medical Press Limited. The full terms of this license are available at https://www.dovepress.com/terms.php (c) $\mathrm{BY}$ and incorporate the Creative Commons Attribution - Non Commercial (unported, v3.0) License (http://creativecommons.org/licenses/by-nc/3.0/). By accessing the work you hereby accept the Terms. Non-commercial uses of the work are permitted without any further permission from Dove Medical Press Limited, provided the work is properly attributed. For permission for commercial use of this work, please see paragraphs 4.2 and 5 of our Terms (https://www.dovepress.com/terms.php). 
do not always use observational pain tools ${ }^{6}$ and often prefer to rely on their intuition and feelings. ${ }^{7}$ However, the nonuse of observational pain measurement tools is a barrier to adequate pain management in persons with dementia. ${ }^{8}$ Therefore, observational pain measurement tools are an essential addition to pain assessment, especially in persons with dementia living in a nursing home. Consequently, there is a need for more evidence-based observational pain measurement.

In light of these findings, the EU-COST action TD 1005 program Pain Assessment in Patients with Impaired Cognition, especially Dementia, developed a meta-tool: Pain Assessment in Impaired Cognition (PAIC). ${ }^{9}$ The EU-COST action TD 1005 was a 4-year EU initiative (2010-2014), which combined the knowledge of experimental and clinical researchers with that of clinical experts, including developers of (some of the) other observational pain measurement tools. One of the aims of the EU-COST action was for the PAIC to become a universal meta-tool, which 1) comprises the best elements of existing observational instruments and 2) can be used in both daily practice and research.

The PAIC consists of three domains of possible indicators for pain: "facial expressions," "body movements," and "vocalizations" ( Supplementary materials). These carefully chosen domains were based on research by the American Geriatric Society (AGS). ${ }^{9,10}$ The 36 PAIC items were systematically selected based on 12 existing assessment tools, expert opinion, previous research, and the AGS criteria. ${ }^{9}$ These 36 individual items are the main focus of the present study.

In the Netherlands, healthcare workers in nursing homes, such as elderly care physicians (ECPs) and nurses, are likely to be target users of the PAIC. Therefore, the PAIC items should represent/reflect the notion of pain in persons with dementia as perceived by ECPs and nurses. Different notions of pain characteristics might lead to suboptimal communication between physicians and nurses ${ }^{11}$ and hinder adequate pain assessment and treatment.

The aim of this study was to describe the translation and evaluation of the content validity of all individual items of the Dutch version of the meta-tool PAIC. It is important to investigate whether all items are indicative of pain ${ }^{12}$ and whether potential users of the PAIC (ECPs and nurses) consider the different items to be pain-specific, or more specific for other disorders (eg, delirium, dementia, depression, or anxiety disorder).

\section{Materials and methods}

\section{Translation}

\section{Dutch version of the PAIC}

Translation into Dutch followed the forward-backward approach of the Guidelines for Establishing Cultural Equivalence of Instruments. ${ }^{13}$ Forward translation from English into Dutch was performed by two independent translators whose native language is Dutch. The professional translator had no medical background and the second translator was a general practitioner with English as a second language. Both forward translations were compared and combined into one common version. The common forward translation was translated back into English by an independent professional translator whose native language is English and who was experienced in translating measurement instruments. The second back translator was a pediatric nursing oncology consultant, familiar with the development and translation of measurement instruments. Both the back translations were compared and combined, and the final English version was then compared with the original English version. Discrepancies were discussed until consensus was achieved.

Finally, the resulting Dutch version was tested during a "think aloud" test ${ }^{12}$ among nurses working in nursing homes. In this "think aloud" test, three nurses (experienced in the care for persons with dementia) were asked to think out loud while filling out the PAIC. Each nurse rated five video-recordings of persons with dementia. All these persons were admitted to a psychogeriatric ward and filmed during their morning care and mealtime. The goal of this test was to look for cues that indicated where the clarity or translation of the items was inadequate, whether the scoring system used was understandable, and whether there were situations in which rating was not possible.

\section{Content validity \\ Participants}

A questionnaire to assess content validity of the PAIC was administered to potential users, that is, nursing home staff who comprised ECPs $(n=20)$ and nurses $(n=20)$ working in seven different nursing home organizations in the Netherlands. All participants had experience in working with persons with dementia at psychogeriatric wards of a nursing home; henceforth, these ECPs and nurses are referred to as "clinical experts."

\section{Questionnaire}

The questionnaire consisted of five general questions: 1) What is your profession? 2) What is your age? 3) Do you feel 
competent to estimate if a person with dementia is in pain? 4) Are pain measurement tools used in your organization? and 5) How often do you use a pain measurement tool?

Next, the clinical experts were asked their opinion about the different items per domain of the PAIC. They were asked whether they considered an item to be indicative of pain, responding on a 4-point Likert scale, that is, 1) no, definitely not; 2) no, probably not; 3 ) yes, probably; and 4) yes, definitely.

They were also asked to indicate whether the different items were most specific for pain or for one of the other disorders such as anxiety disorder, delirium, dementia, or depression. The clinical experts were explicitly asked to indicate only one disorder per item.

\section{Statistical analyses}

Descriptive statistics were used to describe the demographic characteristics of the participants. Data were expressed as mean with $\mathrm{SD}$, or medians with interquartile range (IQR), as appropriate.

For the interpretation of content validity of the different items, the sum score was calculated. The 4-point scale was recoded into the following scores: "No, definitely not": -1 , "No, probably not": -0.5 , "Yes, probably": 0.5, and "Yes, definitely": 1.

An item was considered indicative for pain if the mean score was $>0.50$. To visualize disorder specificity, the items were displayed in three different bar charts, representing each domain of the PAIC. An item was considered pain-specific, or specific for another disorder, if at least $50 \%$ of the clinical experts indicated the item to be pain-specific.
The analyses were first conducted for all clinical experts together and then for the ECPs and nurses separately.

Analyses were performed with IBM SPSS Statistics version 20.0 for Windows.

\section{Results \\ Translation}

The PAIC has been translated and culturally adapted for the Netherlands (Supplementary materials). In the "think aloud" test, all items of the Dutch version of the PAIC were found useful in detecting pain and also relatively easy to score in the clinical setting. The few criticisms made were related to semantics and to the interpretation of some items. For example, nurses questioned whether the item "opened mouth" referred to the active movement of opening the mouth, or whether the item referred to the static state in which the mouth was already open.

\section{Clinical experts}

The clinical experts consisted of 20 ECPs and 20 nurses (Table 1$)$. The majority was female $(80 \%)$, and the total mean score on "feeling competent to assess pain in persons with dementia" was 7.5 (SD 1.3) on a 1-10 Likert scale, on which higher scores indicate a higher level of competence. ECPs and nurses felt equally competent to estimate pain in persons with dementia, that is, median 7.0 (IQR 6.5-8.1) and 7.6 (IQR 7.0-9.4), respectively.

Of the clinical experts, $72 \%$ indicated that some form of pain measurement tool was implemented in their organization but was hardly used; only $14 \%$ used such a tool once or twice a month.

Table I Characteristics of the clinical experts

\begin{tabular}{|c|c|c|c|}
\hline Characteristics & Elderly care physicians & Nurses & Total \\
\hline \multirow[t]{3}{*}{ Gender, female } & $(n=20)$ & $(n=20)$ & $(n=40)$ \\
\hline & $12(60 \%)$ & $20(100 \%)$ & $32(80 \%)$ \\
\hline & $(n=20)$ & $(n=16)^{*}$ & $(n=36)^{*}$ \\
\hline Feeling competent to assess pain in & 7.0 (IQR 6.5-8.I) & 7.6 (IQR 7.0-9.4) & 7.5 (SD I.3) \\
\hline \multicolumn{4}{|l|}{ patients with dementia (Likert scale 0-10) } \\
\hline \multicolumn{4}{|c|}{ Implementation of pain measurement instrument } \\
\hline \multicolumn{4}{|l|}{ in nursing home } \\
\hline Yes & $17(85 \%)$ & $9(56 \%)$ & $26(72 \%)$ \\
\hline No & $3(15 \%)$ & 7 (44 \%) & $10(28 \%)$ \\
\hline \multicolumn{4}{|c|}{ How often do you use pain measurement instruments } \\
\hline \multicolumn{4}{|l|}{ in daily practice? } \\
\hline Never & $3(15 \%)$ & $8(50 \%)$ & II (3|\%) \\
\hline$<\mathrm{I}$ month & $8(40 \%)$ & $8(50 \%)$ & $16(44 \%)$ \\
\hline $\mathrm{I}-2$ month & $5(25 \%)$ & - & $5(14 \%)$ \\
\hline I week & $3(15 \%)$ & - & $3(8 \%)$ \\
\hline Almost daily & I (5\%) & - & I (3\%) \\
\hline
\end{tabular}

Note: *Lower $\mathrm{n}$ due to missing items.

Abbreviation: IQR, interquartile range. 
Compared to ECPs, nurses less often used a pain measurement tool. For example, no nurse used a tool monthly (or more) compared with $45 \%$ of the ECPs.

\section{PAIC items indicative of pain}

Table 2 presents the scores of all the clinical experts together, and ECPs and nurses separately, on how indicative the PAIC items are to detect pain. For each item, the mean (SD) of sumscores is presented.

\section{Facial expressions}

Of the 15 facial expression items, "pained expression" and "frowning" had the highest mean score: 0.90 (SD 0.20) and
0.54 (SD 0.41), respectively (Table 2). Five items had a mean score below zero, with the lowest mean scores of -0.45 (SD 0.54) and -0.50 (SD 0.56) for "empty gaze" and "seeming disinterested," respectively, indicating that these items were considered less indicative of pain.

In the subgroup of ECPs, the items "pained expression" and "frowning" were also considered indicative of pain. This was also true for the subgroup of nurses, although the item "frowning" did not reach the level of $>0.50$. Additionally, nurses also considered "tightened lips" 0.53 (SD 0.61), "looking tense" 0.53 (SD 0.50), and "looking frightened" 0.55 (SD 0.58) to be indicative of pain.

Table 2 Scoring of PAIC items on question indicative of pain and on question specific for pain

\begin{tabular}{|c|c|c|c|c|c|c|}
\hline \multirow[t]{2}{*}{ PAIC items } & \multicolumn{2}{|c|}{ Clinical experts $(n=40)$} & \multicolumn{2}{|l|}{$\operatorname{ECPs}(n=20)$} & \multicolumn{2}{|l|}{ Nurses $(n=20)$} \\
\hline & $\begin{array}{l}\text { Indicative of pain } \\
\text { (mean, SD)* }\end{array}$ & $\begin{array}{l}\text { Specific } \\
\text { for pain }^{\S}\end{array}$ & $\begin{array}{l}\text { Indicative of pain } \\
\text { (mean, SD)* }\end{array}$ & $\begin{array}{l}\text { Specific } \\
\text { for pain }\end{array}$ & $\begin{array}{l}\text { Indicative of pain } \\
\text { (mean, SD)* }\end{array}$ & $\begin{array}{l}\text { Specific } \\
\text { for pain }\end{array}$ \\
\hline \multicolumn{7}{|l|}{ Facial expressions } \\
\hline Pained expression & $0.90(0.20)$ & $\mathbf{x}$ & $0.88(0.22)$ & $\mathbf{x}$ & $0.93(0.18)$ & $\mathbf{x}$ \\
\hline Frowning & $0.54(0.4 I)$ & $\mathbf{x}$ & $0.58(0.18)$ & $\mathbf{x}$ & $0.50(0.56)$ & \\
\hline Narrowing eyes & $0.27(0.52)$ & $x$ & $0.45(0.36)$ & $x$ & $0.13(0.60)$ & $x$ \\
\hline Closing eyes & $-0.05(0.61)$ & & $-0.20(0.55)$ & & $0.10(0.64)$ & \\
\hline Raising upper lip & $0.15(0.58)$ & $x$ & $0.11(0.54)$ & $x$ & $0.20(0.62)$ & $x$ \\
\hline Opened mouth & $-0.23(0.62)$ & & $-0.40(0.50)$ & & $-0.05(0.69)$ & \\
\hline Tightened lips & $0.4 \mathrm{I}(0.52)$ & $x$ & $0.30(0.4 \mathrm{I})$ & $x$ & $0.53(0.6 \mathrm{I})$ & $\mathbf{x}$ \\
\hline Clenched teeth & $0.4 I(0.52)$ & $x$ & $0.45(0.36)$ & $x$ & $0.36(0.66)$ & $x$ \\
\hline Empty gaze & $-0.45(0.54)$ & & $-0.60(0.35)$ & & $-0.29(0.65)$ & \\
\hline Seeming disinterested & $-0.50(0.56)$ & & $-0.75(0.26)$ & & $-0.24(0.67)$ & \\
\hline Pale face & $-0.27(0.61)$ & & $-0.50(0.4 I)$ & & $-0.02(0.70)$ & $x$ \\
\hline Teary eyed & $0.13(0.63)$ & & $0.00(0.58)$ & & $0.25(0.66)$ & $x$ \\
\hline Looking tense & $0.44(0.48)$ & & $0.35(0.46)$ & & $0.53(0.50)$ & \\
\hline Looking sad & $0.10(0.68)$ & & $-0.08(0.54)$ & & $0.29(0.77)$ & \\
\hline Looking frightened & $0.49(0.58)$ & & $0.4 \mathrm{I}(0.58)$ & & $0.55(0.58)$ & \\
\hline \multicolumn{7}{|l|}{ Body movements } \\
\hline Freezing & $0.65(0.36)$ & $\mathbf{x}$ & $0.70(0.25)$ & & $0.60(0.45)$ & $\mathbf{x}$ \\
\hline Curling up & $0.69(0.37)$ & $\mathbf{x}$ & $0.78(0.26)$ & $\mathbf{x}$ & $0.60(0.44)$ & \\
\hline Clenching hands & $0.4 \mathrm{I}(0.47)$ & & $0.45(0.36)$ & & $0.38(0.56)$ & \\
\hline Resisting care & $0.19(0.49)$ & & $0.17(0.49)$ & & $0.23(0.53)$ & \\
\hline Pushing & $0.33(0.58)$ & & $0.20(0.55)$ & & $0.45(0.60)$ & \\
\hline Guarding & $0.65(0.41)$ & $\mathbf{x}$ & $0.68(0.37)$ & $\mathbf{x}$ & $0.63(0.46)$ & $\mathbf{x}$ \\
\hline Rubbing & $0.54(0.42)$ & $\mathbf{x}$ & $0.53(0.41)$ & $\mathbf{x}$ & $0.55(0.44)$ & $\mathbf{x}$ \\
\hline Limping & $0.68(0.42)$ & $\mathbf{x}$ & $0.63(0.46)$ & $x$ & $0.73(0.38)$ & $x$ \\
\hline Restlessness & $0.23(0.57)$ & & $0.08(0.46)$ & & $0.38(0.56)$ & \\
\hline Pacing & $0.09(0.62)$ & & $-0.05(0.58)$ & & $0.23(0.64)$ & \\
\hline \multicolumn{7}{|l|}{ Vocalizations } \\
\hline Using offensive words & $0.23(0.55)$ & & $0.13(0.54)$ & & $0.34(0.55)$ & \\
\hline Using pain-related words & $0.90(0.29)$ & $\mathbf{x}$ & $0.89(0.21)$ & $\mathbf{x}$ & $0.90(0.35)$ & $\mathbf{x}$ \\
\hline Repeating words & $-0.26(0.53)$ & & $-0.33(0.52)$ & & $-0.20(0.55)$ & \\
\hline Complaining & $0.64(0.36)$ & $\mathbf{x}$ & $0.65(0.24)$ & $\mathbf{x}$ & $0.63(0.46)$ & \\
\hline Shouting & $0.03(0.58)$ & & $-0.05(0.58)$ & & $0.10(0.58)$ & \\
\hline Mumbling & $-0.18(0.55)$ & & $-0.35(0.46)$ & & $0.00(0.58)$ & \\
\hline Screaming & $0.26(0.53)$ & & $0.15(0.56)$ & & $0.38(0.48)$ & \\
\hline Groaning & $0.7 \mid(0.32)$ & $\mathbf{x}$ & $0.66(0.37)$ & $x$ & $0.75(0.26)$ & $x$ \\
\hline Crying & $0.60(0.40)$ & & $0.53(0.4 I)$ & & $0.68(0.37)$ & $x$ \\
\hline Gasping & $0.35(0.57)$ & $x$ & $0.35(0.54)$ & & $0.35(0.61)$ & $x$ \\
\hline Sighing & $0.14(0.58)$ & & $0.10(0.58)$ & & $0.18(0.59)$ & $x$ \\
\hline
\end{tabular}

Notes: *Mean score $>0.50$ considered content valid. ${ }^{\S}$ When marked with an "X," at least $50 \%$ of clinical experts rated the item as specific for pain. Bold entries indicate PAIC items indicative of pain as well as specific for pain.

Abbreviations: PAIC, Pain Assessment in Impaired Cognition; ECP, elderly care physician. 


\section{Body movements}

In the body movements domain, as none of the items scored below zero, all items were considered indicative of pain. Five items had a mean score $>0.50$ : "freezing" $(0.65$, SD 0.36$)$, "curling up" (0.69, SD 0.37), "guarding" (0.65, SD 0.41), "rubbing" (0.54, SD 0.42), and "limping" (0.68, SD 0.42).

Subgroup analyses showed no difference between ECPs and nurses compared to the whole sample, with the exception of the item "pacing." On average, nurses considered "pacing" to be probably indicative of pain, as opposed to ECPs who considered the item to be probably not indicative of pain.

\section{Vocalizations}

Four items of the vocalizations domain had mean scores $>0.50$ : "complaining," "groaning," and "crying," with the highest mean score of 0.90 (SD 0.29) for the item "using pain-related words." This applied to both the subgroups of the clinical experts.

Two items were considered not indicative of pain: "repeating words" -0.26 (SD 0.53) and "mumbling" -0.18 (SD 0.55 ). The only item with low mean scores assigned by both ECPs and nurses was "repeating words": -0.33 (SD 0.52) and -0.20 (SD 0.55), respectively.

\section{PAIC items specific for pain}

Figures 1-3 show whether the clinical experts considered the different items of the PAIC to be pain-specific, or more specific for other disorders. An item was considered specific for a disorder when (at least) 20 out of 40 clinical experts rated it as such. Furthermore, Table 2 also shows which items were considered specific for pain. An item was considered specific for a disorder when (at least) $50 \%$ of the clinical experts and (at least) $50 \%$ of the ECPs and nurses rated it as such (marked with "x").

\section{Facial expressions}

The clinical experts indicated six items to be pain-specific: "pained expression," "frowning," "narrowing eyes," "raising upper lip," "tightened lips," and "clenched teeth" (Figure 1). The remaining items were indicated to be more specific for one of the other disorders: anxiety disorder, depression, and dementia. For example, the items "looking tense" and "looking frightened" were indicated to be most specific for anxiety disorder, the items "opened mouth" and "empty gaze" for dementia, and the item "looking sad" for depression. Facial expressions were seldom found to be specific for delirium.

Subgroup analyses showed that ECPs rated some items to be more specific for depression (Supplementary materials).

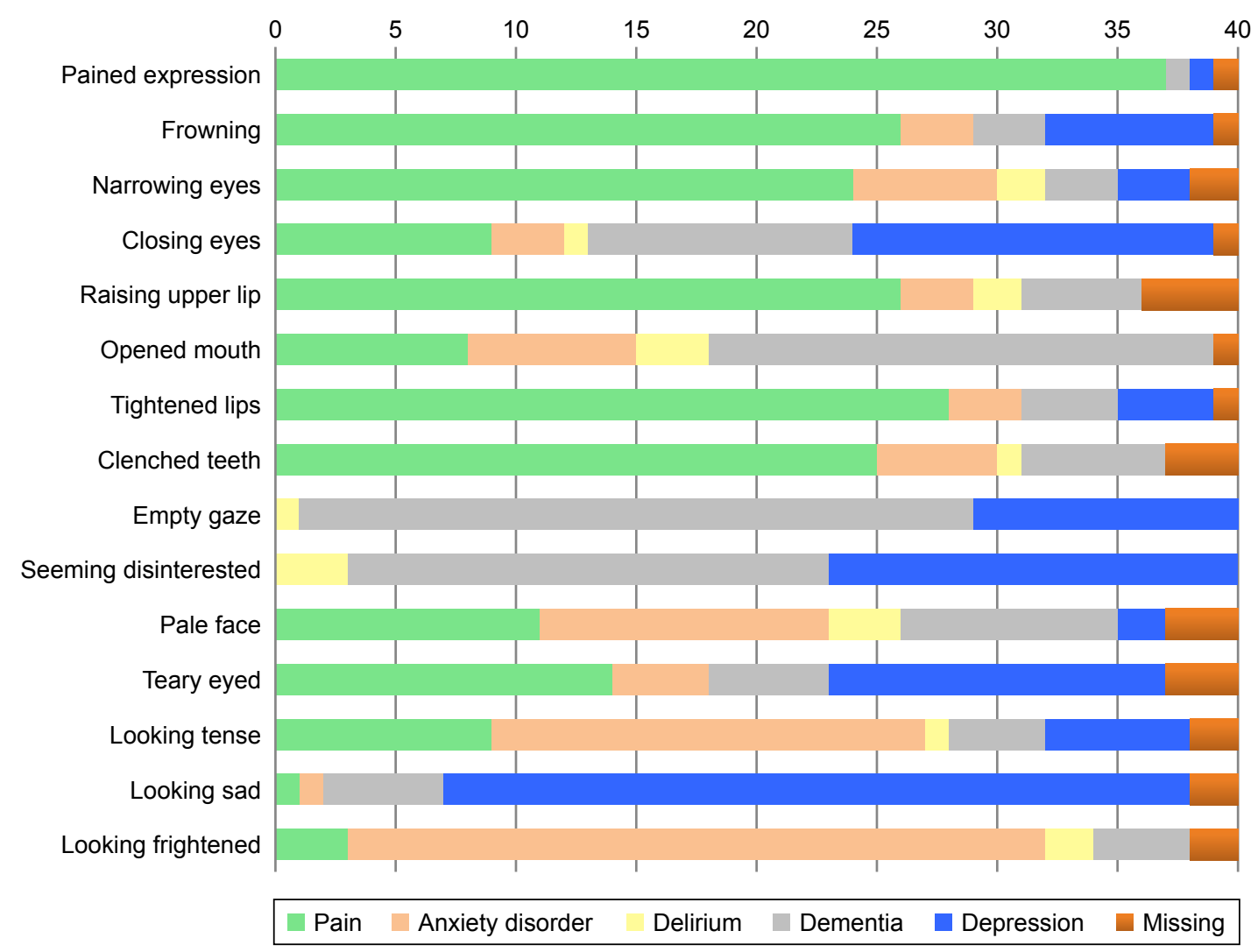

Figure I Facial expressions considered pain-specific or specific for other disorders by the clinical experts $(n=40)$ 


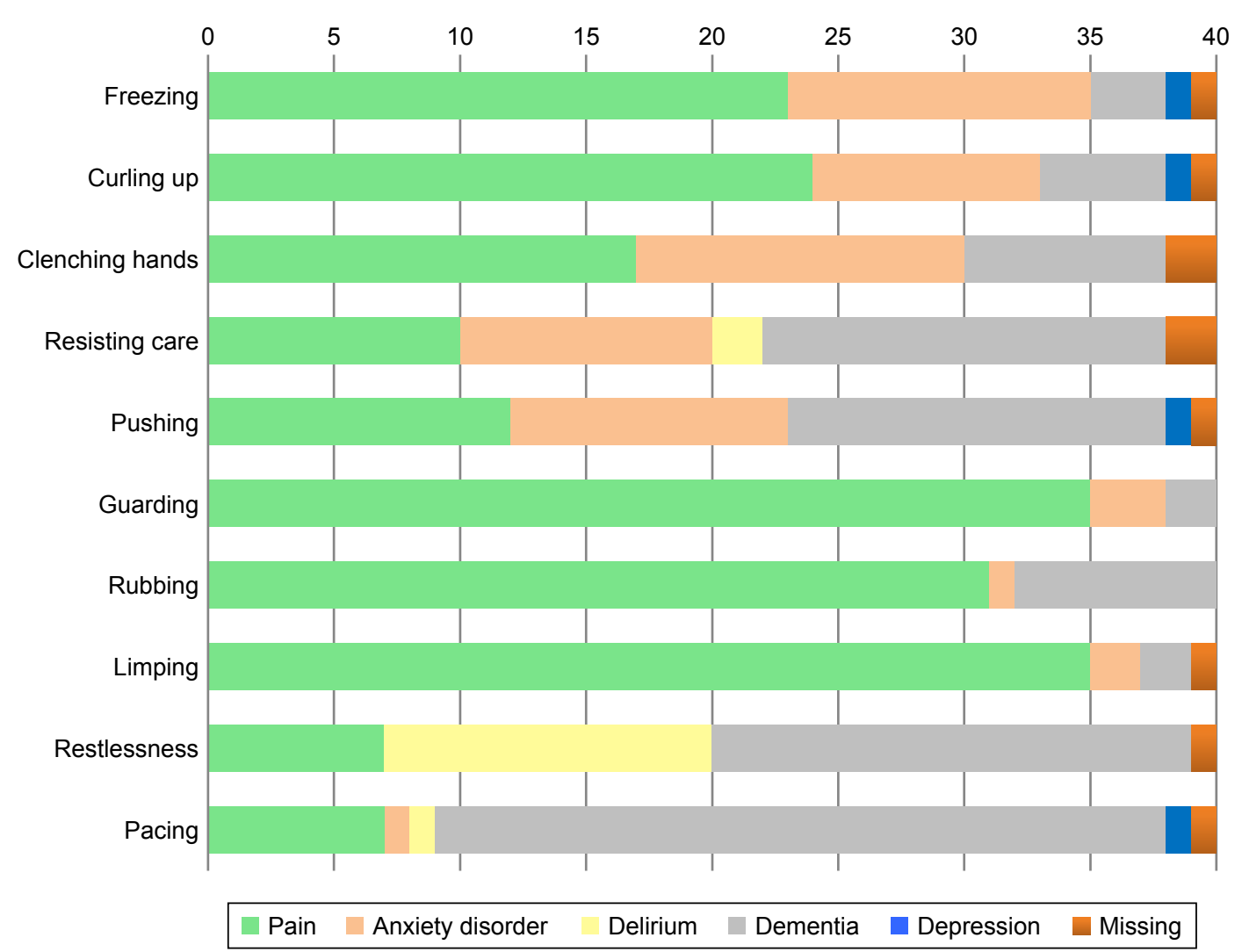

Figure 2 Body movements considered pain-specific or specific for other disorders by the clinical experts $(n=40)$.

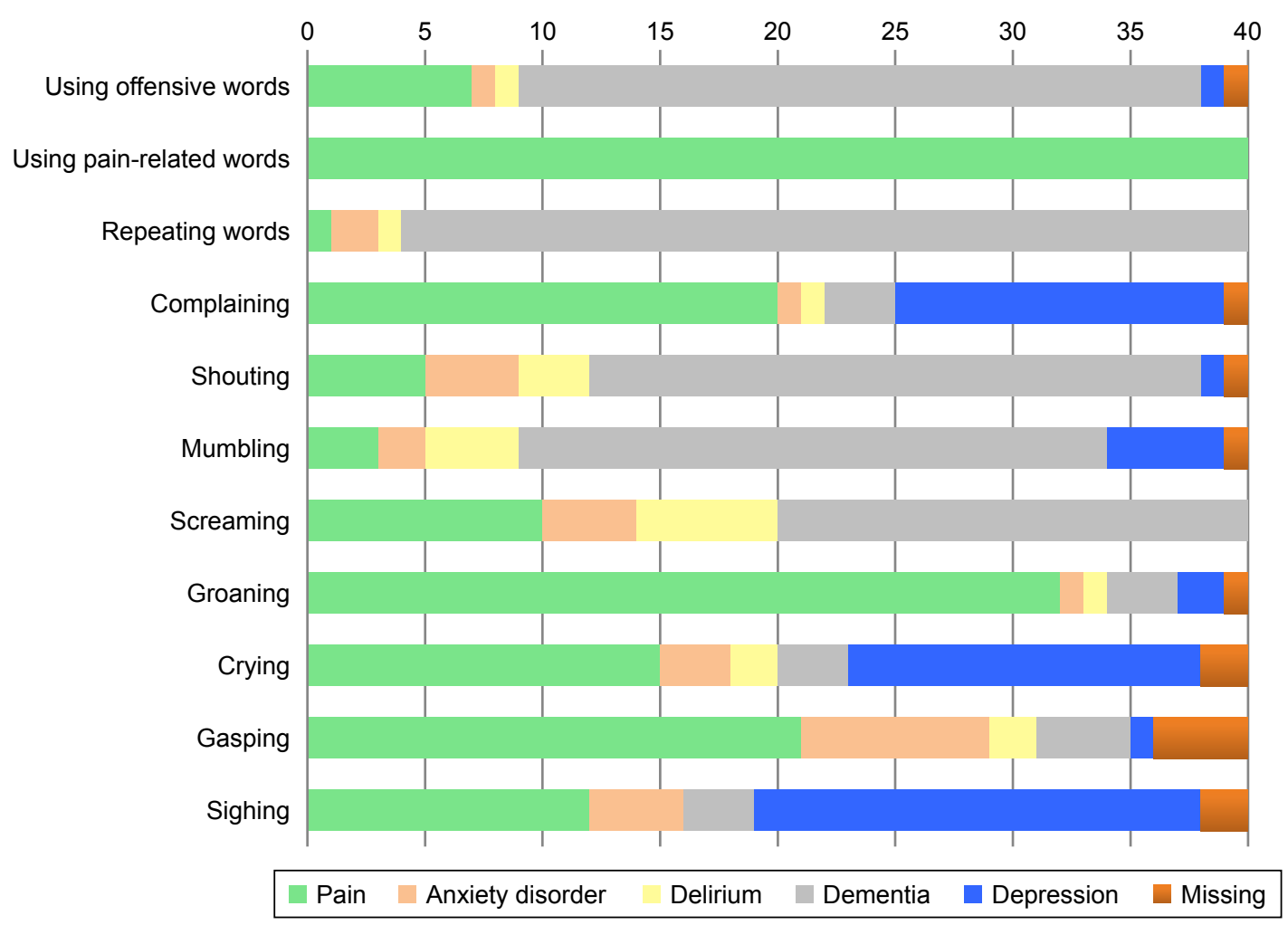

Figure 3 Vocalizations considered pain-specific or specific for other disorders by the clinical experts $(n=40)$. 
Especially, the items "closing eyes," "seeming disinterested," "teary eyed," and "looking sad" were considered to be most specific for depression. On the other hand, nurses only indicated "looking sad" to be most specific for depression. Additionally, nurses indicated the item "pale face" to be painspecific, whereas ECPs indicated the item to be most specific for anxiety disorder. Both ECPs and nurses considered the item "empty gaze" not to be pain-specific at all; this item was found to be most specific for dementia.

\section{Body movements}

Of the 10 items in the body movements domain, half were indicated to be pain-specific: "freezing," "curling up," "guarding," "rubbing," and "limping" (Figure 2). The item "pacing" was indicated to be most specific for dementia itself, as was the item "restlessness." The items of the body movements domain were often considered not to be specific for the disorders delirium and depression.

There was a substantial agreement between ECPs and nurses. They indicated most of the body movements to be most specific for pain and dementia (Supplementary materials). Furthermore, both ECPs and nurses indicated that some items were specific for an anxiety disorder, for example, "resisting care" and "clenching hands." According to ECPs and nurses, depression was almost never related to the items of the body movements domain.

\section{Vocalizations}

The items "using pain-related words," "complaining," "groaning," and "gasping" were indicated to be most painspecific (Figure 3); however, the item "complaining" was also considered specific for depression. The clinical experts indicated five items to be most specific for dementia: "using offensive words," "repeating words," "shouting," "mumbling," and "screaming."

"Crying" and "sighing" were found to be specific for depression, but were also considered pain-specific. Overall, the items of the vocalizations domain were not often found to be specific for the disorder delirium.

The item "pain-related words" was considered to be definitely pain-specific and not specific for one of the other disorders. This also applied on the subgroup level (Supplementary materials).

\section{Discussion}

In this study, the PAIC was translated into Dutch and content validity was examined. Overall, the study suggests that especially the items of the body movements domain correspond well with the clinical experience of the ECPs and nurses in Dutch nursing homes and showed good content validity. Compared with the body movements domain, lower content validity was shown for a number of items of the facial expressions domain and, to a lesser extent, for items of the vocalizations domain.

In total, 11 items $(30.6 \%)$ had mean scores of $>0.50$ and were considered most definitely indicative of pain: "pained expression," "frowning," "freezing," "curling up," "guarding," "rubbing," "limping," "using pain-related words," "complaining," "groaning," and "crying." However, six items with lower scores may still be promising, as they were found to be most pain-specific: "clenched teeth," "tightened lips," "raising upper lip," "narrowing eyes," "gasping," and "complaining." The remaining items were found to be most specific for one of the other disorders, that is, anxiety disorder, delirium, depression, or dementia. More importantly, 10 items were considered indicative of pain as well as specific for pain: "pained expression," "frowning," "freezing," "curling up," "guarding," "rubbing," "limping," "using pain-related words," "complaining," and "groaning." This suggests that these items fit most with the opinion of the clinical experts and are, therefore, promising items in the measurement of pain.

Surprisingly, of the 11 items considered indicative of pain by ECPs and nurses, only two belonged to the facial expressions domain. Also, according to ECPs, several items of the facial expressions domain are more specific for depression or an anxiety disorder. This is remarkable because the items included in the PAIC were carefully selected by an expert panel from existing observational pain measurement instruments. ${ }^{9}$ Based on that selection procedure, one would expect more items of the facial expressions domain to have good content validity. Even more striking is that, in an experimental setting, facial expressions are found to be most specific for pain, especially in persons with dementia. ${ }^{14-16}$ Thus, this might suggest that the translation from bench to bedside does not fit the clinical notion of expressions of pain.

Additionally, there was a discrepancy between items considered indicative of pain and items considered painspecific. For example, the items "narrowing eyes," "raising upper lip," "clenched teeth," and "tightening lips" had mean scores below 0.50; although they were considered less indicative of pain, they were considered more painspecific compared to the other disorders (Table 2 and Figure 1). Interestingly, compared to ECPs, nurses found more items indicative of pain and also more items specific for pain. 
These findings reveal not only a discrepancy between items being indicative of pain, but also a discrepancy between the notion of pain characteristics in dementia according to nurses and ECPs. This might be due to a lack of education of healthcare workers in the nursing home on pain assessment and management of persons with dementia. ${ }^{17}$ Moreover, a lack of training and education can present a barrier to adequate pain management. ${ }^{8}$ A lack of empirical evidence regarding which symptoms and behaviors are really related to pain might also play a role in this discrepancy. Since pain is an individual and personal experience, which is influenced by training and experience, healthcare workers may not think alike when identifying signs and symptoms of pain in persons with dementia. ${ }^{18}$ This discrepancy adds to the already difficult challenge of identifying pain in persons with dementia.

It is most important that nurses and physicians speak the same language and recognize the same items as pain indicators to achieve adequate pain management, especially since nurses play a key role in the care for and monitoring of symptoms in persons with dementia.

Interestingly, such discrepancies did not exist for the items of the body movements domain. First, there were no major discrepancies between items being indicative of pain versus items being pain-specific. In other words, all those items considered most definitely indicative of pain were also considered most pain-specific. Second, this domain showed hardly any differences between the nurses' and ECPs' notion of pain characteristics. The mean scores of nurses and ECPs separately did not differ, except for the item "pacing" which ECPs rated with a mean score of -0.05 (SD 0.58) compared to 0.23 (SD 0.64 ) by nurses. In both the groups, "pacing" was found most specific for dementia.

Regarding the items of the vocalizations domain, the clinical experts indicated four items most definitely indicative of pain: "crying," "groaning," "complaining," and "using pain-related words." Of those items, "groaning," "complaining," and "using pain-related words" were also found to be most pain-specific. No major discrepancies were found between nurses and ECPs on items of the vocalizations domain. Surprisingly, despite the high mean score of the item "crying" $(0.60$, SD 0.40$)$, the clinical experts indicated "crying" to be less pain-specific compared to the other disorders. In fact, the item "crying" was also found to be specific for depression. Furthermore, the item "gasping" had a low mean score on being indicative of pain ( 0.35 , SD 0.57), but was indeed considered pain-specific. Moreover, more than half of the items were found to be less indicative of pain and, remarkably, several items of the vocalizations domain were indicated to be also specific for dementia. This might suggest that nurses and ECPs do not interpret most of the vocalization items as an evident expression of pain.

A possible explanation for the overall agreement between nurses and ECPs on the items of the body movements and vocalizations domain might be that pain-related body movements and vocalizations are more easily recognized than facial expressions of pain, ${ }^{19,20}$ which require more specific training and education. ${ }^{21}$ However, a recent study by Lautenbacher et al showed that nurses caring for persons with dementia already focus on certain facial expressions like "narrowed eyes" and "frowning," without specific training. ${ }^{22}$ Again, this emphasizes the need for additional, improved, and interdisciplinary education on pain recognition in dementia. ${ }^{23}$

\section{Strengths and limitations}

The strength of the present study is that the content validity was examined separately among ECPs and nurses. It is important that the content of a measurement instrument contains the views and beliefs of the potential users. This is also called "user-centeredness" and is considered an important part of developing and testing a new measurement instrument. ${ }^{24}$ Ultimately, this will contribute to better psychometric properties and feasibility of implementation of observational instruments, such as the PAIC.

Furthermore, our sample size was larger compared to other studies investigating psychometric properties of observational pain measurement tools. ${ }^{5}$ A larger sample size provides more solid results in terms of content validity.

A possible limitation is that content validity is a subjective assessment and no standardized procedures are available to investigate this. Moreover, most studies investigating observational pain tools do not report on content validity, despite that this is an important part of psychometrics, also with respect to feasibility of implementation. ${ }^{5,25}$ When content and face validity are missing, this might be a good reason not to use that specific measurement instrument. ${ }^{12}$

Additionally, in this study, the clinical experts were asked to indicate whether the items of the PAIC were most specific for pain, or for one of the other (fixed) disorders. They could indicate only one disorder per item, for example, anxiety disorder, delirium, dementia, depression, or pain. However, because these preselected disorders may not fully represent the opinion of the experts, some crucial information could have been missed. For example, one could suggest that the 
item "pale face" is specific for Parkinson's disease, whereas this could not be indicated as such.

Furthermore, the items of the PAIC in this study were not assessed on prevalence in persons with dementia who experience pain; rather, the potential users of the PAIC were asked their clinical opinion about the items. However, the potential users of this study were considered clinical experts with considerable experience in the care for persons with dementia. Furthermore, we did not ask the clinical opinion of healthcare assistants or nursing auxiliaries as they could play an important role in the recognition of a change in behaviour. They could provide additional information on possible cues for pain.

Finally, since this study concerns validating the Dutch version of the PAIC, it is possible that, due to differences in culture and training, the results may not be generalizable to other countries.

\section{Clinical implications}

Besides establishing the content validity of the PAIC, this study also has clinical implications. For example, the study sheds light on the opinion of physicians and nurses regarding the cues used to decide whether a person with dementia is in pain. The study also reveals important differences of opinion between physicians and nurses. This information suggests that educational shortcomings may exist (especially interdisciplinary education) among healthcare workers in nursing homes. The study also provides insight into the empirical performance of the PAIC.

Due to its solid scientific basis, the PAIC seems a promising assessment tool. ${ }^{9}$ However, a lack of empirical evidence and of interdisciplinary education on pain in dementia could be a barrier to adequate pain management and treatment. Therefore, in addition to aiming to create the most valid/reliable assessment tool to measure pain in persons with dementia, it is also important to provide education on pain in dementia and training in the use of observational pain measurement tools. Also, considering that implementation of an observational pain measurement tool does not necessarily lead to better care, ${ }^{26}$ a constant flow of education should be available to maintain a certain level of awareness to ensure adequate management of pain. ${ }^{27-29}$ This validity study reveals, in particular, the need for more education in facial expressions.

\section{Future directions of PAIC}

The first step in testing the Dutch version of the new, universal, meta-tool PAIC was to examine the content validity of a wide range of individual items. To improve and refine the PAIC, item reduction is needed. For this, especially the facial expressions domain and (to a lesser extent) the vocalizations domain need additional study. The next important step is to examine content validity in other countries, so that the PAIC can become an internationally agreed upon observational measurement tool. Also, by investigating content validity in a larger population, factor analyses can be used to determine which items correlate with each other. ${ }^{12}$ For example, if the different domains of the PAIC cluster together, a decision could be made to measure pain using the domain that corresponds most with the clinical experience and, therefore, is the easiest to score. Based on the present study, the body movements domain would be the most suitable to measure pain in persons with dementia.

It might also be worthwhile to investigate if solely those items with good content validity (eg, both indicative of pain and specific for pain) are sufficient for the measurement of pain in persons with dementia. In that case, this study suggests that the PAIC could be reduced from 36 items to only 10 items. However, although a shorter measurement tool might offer more advantages (eg, easier to use, less timeconsuming) with regard to feasibility, clinical utility, and implementation in clinical/research settings, further testing using, for example factor analyses is needed.

\section{Conclusion}

This study shows that the Dutch version of the PAIC has overall good content validity but that differences exist in the notion of pain characteristics between nurses and physicians working in nursing homes. This important information indicates a need for more, interdisciplinary, education on pain in dementia. However, before implementing the PAIC in clinical and research settings, it is necessary to further test the reliability, clinical utility, and feasibility. Additionally, investment in more education of physicians and nurses might be required to accomplish more successful management of pain in persons with dementia.

\section{Acknowledgments}

The authors thank all the physicians and nurses who participated in the clinical expert panel of this study. This study was supported by the SBOH (employer of elderly care medicine/ general practitioner trainees).

\section{Disclosure}

The authors report no conflicts of interest in this work. 


\section{References}

1. Achterberg WP, Pieper MJ, van Dalen-Kok AH, et al. Pain management in patients with dementia. Clin Interv Aging. 2013;8:1471-1482.

2. Warden V, Hurley AC, Volicer L. Development and psychometric evaluation of the Pain Assessment in Advanced Dementia (PAINAD) scale. J Am Med Dir Assoc. 2003;4(1):9-15.

3. Fuchs-Lacelle S, Hadjistavropoulos T. Development and preliminary validation of the pain assessment checklist for seniors with limited ability to communicate (PACSLAC). Pain Manag Nurs. 2004;5(1): $37-49$.

4. Husebo BS, Strand LI, Moe-Nilssen R, Husebo SB, Snow AL, Ljunggren AE. Mobilization-Observation-Behavior-IntensityDementia Pain Scale (MOBID): development and validation of a nurse-administered pain assessment tool for use in dementia. J Pain Symptom Manage. 2007;34(1):67-80.

5. Lichtner V, Dowding D, Esterhuizen P, et al. Pain assessment for people with dementia: a systematic review of systematic reviews of pain assessment tools. BMC Geriatr. 2014;14:138.

6. Manias E. Complexities of pain assessment and management in hospitalised older people: a qualitative observation and interview study. Int J Nurs Stud. 2012;49(10):1243-1254.

7. Parke B. Gerontological nurses' ways of knowing. Realizing the presence of pain in cognitively impaired older adults. $J$ Gerontol Nurs. 1998;24(6):21-28.

8. McAuliffe L, Nay R, O’Donnell M, Fetherstonhaugh D. Pain assessment in older people with dementia: literature review. J Adv Nurs. 2009;65(1):2-10.

9. Corbett A, Achterberg W, Husebo B, et al. An international road map to improve pain assessment in people with impaired cognition: the development of the Pain Assessment in Impaired Cognition (PAIC) meta-tool. BMC Neurol. 2014;14(1):229.

10. AGS PoPPiOP. The management of persistent pain in older persons. J Am Geriatr Soc. 2002;50(6 Suppl):S205-S224.

11. Peisah C, Weaver J, Wong L, Strukovski JA. Silent and suffering: a pilot study exploring gaps between theory and practice in pain management for people with severe dementia in residential aged care facilities. Clin Interv Aging. 2014;9:1767-1774.

12. De Vet HC, Terwee CB, Mokkink LB, Knol DL. Measurement in Medicine: A Practical Guide. New York: Cambridge University Press; 2011.

13. Ohrbach R, Bjorner J, Jezewski M, John M, Lobbezoo F. Guidelines for Establishing Cultural Equivalency of Instruments. New York: University at Buffalo; 2009.

14. Kunz M, Scharmann S, Hemmeter U, Schepelmann K, Lautenbacher S. The facial expression of pain in patients with dementia. Pain. 2007; 133(1-3):221-228.
15. Kunz M, Mylius V, Scharmann S, Schepelman K, Lautenbacher S. Influence of dementia on multiple components of pain. Eur JPain. 2009;13(3): 317-325.

16. Oosterman JM, Zwakhalen S, Sampson EL, Kunz M. The use of facial expressions for pain assessment purposes in dementia: a narrative review. Neurodegener Dis Manag. 2016;6(2):119-131.

17. Zwakhalen SM, Hamers JP, Peijnenburg RH, Berger MP. Nursing staff knowledge and beliefs about pain in elderly nursing home residents with dementia. Pain Res Manag. 2007;12(3):177-184.

18. Craig KD. The social communication model of pain. Can Psychol. 2009; 50(1):22.

19. Closs SJ, Cash K, Barr B, Briggs M. Cues for the identification of pain in nursing home residents. Int J Nurs Stud. 2005;42(1):3-12.

20. Beach PA, Huck JT, Miranda MM, Foley KT, Bozoki AC. Effects of Alzheimer disease on the facial expression of pain. Clin J Pain. 2016; 32(6):478-487.

21. Oosterman JM, van Harten B, Weinstein HC, Scheltens P, Scherder EJA. Pain intensity and pain affect in relation to white matter changes. Pain. 2006;125(1-2):74-81.

22. Lautenbacher S, Sampson EL, Pahl S, Kunz M. Which facial descriptors do care home nurses use to infer whether a person with dementia is in pain? Pain Med. 2016 Epub Dec 29.

23. Burns M, McIlfatrick S. Nurses' knowledge and attitudes towards pain assessment for people with dementia in a nursing home setting. Int $J$ Palliat Nurs. 2015;21(10):479-485.

24. Long F. Reviewing and selecting outcome measures for use in routine practice. J Eval Clin Pract. 1998;4(4):339-350.

25. Zwakhalen SM, Hamers JP, Berger MP. The psychometric quality and clinical usefulness of three pain assessment tools for elderly people with dementia. Pain. 2006;126(1-3):210-220.

26. Zwakhalen SM, van't Hof CE, Hamers JP. Systematic pain assessment using an observational scale in nursing home residents with dementia: exploring feasibility and applied interventions. J Clin Nurs. 2012;21(21-22):3009-3017.

27. Long CO. Pain management education in long-term care: it can make a difference. Pain Manag Nurs. 2013;14(4):220-227.

28. Ghandehari OO, Hadjistavropoulos T, Williams J, et al. A controlled investigation of continuing pain education for long-term care staff. Pain Res Manag. 2013;18(1):11-18.

29. Jansen BW, Brazil K, Passmore P, et al. Exploring healthcare assistants' role and experience in pain assessment and management for people with advanced dementia towards the end of life: a qualitative study. BMC Palliat Care. 2017;16(1):6.
Clinical Interventions in Aging

\section{Publish your work in this journal}

Clinical Interventions in Aging is an international, peer-reviewed journal focusing on evidence-based reports on the value or lack thereof of treatments intended to prevent or delay the onset of maladaptive correlates of aging in human beings. This journal is indexed on PubMed Central, MedLine,

\section{Dovepress}

CAS, Scopus and the Elsevier Bibliographic databases. The manuscript management system is completely online and includes a very quick and fair peer-review system, which is all easy to use. Visit http://www.dovepress. com/testimonials.php to read real quotes from published authors. 